\title{
Tokarczyk, Michelle M. (2016) Bronx Migrations, Cherry Castle Publishing, Columbia, Md.
}

\section{Review by Jim Daniels}

With the publication of Bronx Migrations, Michelle Tokarczyk has put herself on the map as a poet of place. Place, and class, for those two things go hand in hand throughout this powerful debut collection centered on her native turf, the Bronx. Certain 'places' seem to be avoided in much of our culture, our literature, and, in particular, much of our poetry-like suburbanites afraid to venture into our big cities.

If not avoided, then distorted, as Tokarczyk details in 'On Fort Apache, the Movie,' when, in the final section, 'Lights on, Talking Back,' she writes: 'Something weighs in me,/like the heaviness I feel/when I hear Spanish/and understand/only the shouting.//What about the chidren/playing ball outside the precinct?//Think about the people sitting/in windows staring past/their twelve-hour shifts.'

Tokarczyk, a leader in the Working Class Studies Association and a respected scholar on writing and class, has made an impressive poetic debut with this collection, showing the depth and insight of a veteran poet. Bronx Migrations offers up rich details of her childhood - her family history, her personal story-in this rich, autobiographical collection that tells the story of a neighborhood's transition and the complications of race and class that influence her family's struggles. In 'Left Behind,' she tells the story of one family, the Harpers, who stayed in the old neighborhood while most everyone else left: 'First Ricky, then Jim, then the Connollys/next door. Then the Burns who lived/down the hall. Even the blacks and Spanish/who moved here years ago...left.' The price paid for staying? 'Everyone looked at their Irish eyes/and the subway stop where they got off//and saw failure. 'White trash,' they called it.'

What I admire about this collection is Tokarczyk's awareness of her own biases and preoccupations. She complicates situations like our best poetry does, rather than oversimplify them. For example, in 'Elegy for a Building,' in which she revisits her old neighborhood, we might expect a simple nostalgic elegy for what once was. While 'Empty space holds none of my memories' - the building she lived in is gone-'the space is a playground, its fence shining/fresh silver paint.' At this point, we might expect it to be an easy statement acknowledging the rebirth of the neighborhood with new immigrants, but the poem shifts again in its powerful conclusion, recognizing both that the children on the playground are 'unaware their neighborhood has been reborn' and that they are 'oblivious to me, as I mourn.'

The voice in these poems is direct, accessible, and strong. Tokarczyk is an unflinching guide to her community, joining the ranks of poets like the late Patricia Dobler, whose Talking to Strangers focuses on Middletown, the Ohio mill town 
where she grew up; and more recently Sandee Gertz Umbach, whose The Pattern Maker's Daughter focuses on Johnstown, Pennsylvania.

Like those poets, Tokarczyk doesn't gloss over her community's warts, nor does she glorify them-she gives us an honest appraisal full of love and empathy. As she writes in "Poetry at the Bronx Museum," "Memories made flesh. Made word./Finally heard." While the migrations take place, we always know where her heart is.

\section{Reviewer Bio}

Jim Daniels' next books of poems, Rowing Inland (Wayne State University Press) and Street Calligraphy (Steel Toe Books) will both be published in 2017. A native of Detroit, Daniels is the Thomas Stockham University Professor of English at Carnegie Mellon University. 